\title{
Effects of Whole-root and Half-root Water Stress on Gas Exchange and Chlorophyll Fluorescence Parameters in Apple Trees
}

\author{
Jinhong Yuan and Man Xu \\ Beijing Key Laboratory of Grape Science and Enology, and Key Laboratory of Plant Resource \\ Science, Institute of Botany, Chinese Academy of Sciences, Beijing 100093, P.R. China; and Key \\ Laboratory of Plant Germplasm Enhancement and Speciality Agriculture, Wuhan Botanical Garden, \\ Chinese Academy of Sciences, Wuhan 430074, P.R. China
}

\author{
Wei Duan and Peige Fan \\ Beijing Key Laboratory of Grape Science and Enology, and Key Laboratory of Plant Resource \\ Science, Institute of Botany, Chinese Academy of Sciences, Beijing 100093, P.R. China
}

\author{
Shaohua Li ${ }^{1}$ \\ Key Laboratory of Plant Germplasm Enhancement and Speciality Agriculture, Wuhan Botanical \\ Garden, Chinese Academy of Sciences, Wuhan 430074, P.R. China
}

\begin{abstract}
Additional INDEX wORDs. apple seedlings, half-root water stress, photosynthesis, OJIP test, xanthophylls
Abstract. The responses of photosynthesis, chlorophyll fluorescence, and de-epoxidation state of the xanthophyll cycle pigments (DEPS) of micropropagated apple trees (Malus $\times$ domestica) were investigated under whole-root water stress (WRS) and half-root water stress (HRS) induced by polyethylene glycol 6000 to simulate whole and partial root zone drying. Compared with control plants without water stress, plants under WRS and HRS exhibited reduced leaf net photosynthetic rate $\left(\mathrm{P}_{n}\right)$ and stomatal conductance $\left(g_{S}\right)$ with a greater reduction in WRS than in HRS plants. However, intercellular $\mathrm{CO}_{2}$ concentration $(\mathrm{Ci})$ increased under WRS as water stress was prolonged, signifying a non-stomatal limitation of $P_{n}$. Regarding HRS, decreased $P_{n}$ was mainly the result of a stomatal limitation explained by a relatively low $\mathrm{C} i$. Changes in photosynthesis and chlorophyll parameters indicate that severe and slight damage occurred to the photosynthetic apparatus of WRS and HRS leaves, respectively, starting at Day 3 after initiating water stress. This damage was not evident on the donor side but was expressed as a reduced capacity of the acceptor side of the photosystem II reaction centers. To prevent damage from excess light, the DEPS of WRS leaf increased. Decreased $g_{S}$ could explain reduced water use under an irrigation strategy of partial root zone drying in fruit trees.
\end{abstract}

Water is a limited resource worldwide. Water deficits often result in a decrease of $P_{n}$, which can influence vegetative growth, yield, and fruit quality in fruit trees. The response of photosynthesis to water stress is correlated with stress intensity. Under medium water stress, it has been shown that the close of stomata decreased $\mathrm{CO}_{2}$ concentration at the site of carboxylation, which led to reduction of photosynthetic rate (Chaves, 1991). More serious water deficit conditions may lead to the damage of photosynthetic apparatus, imposing a nonstomatal limitation to photosynthesis (Ennahli and Earl, 2005; Farquhar and Sharkey, 1982).

Partial root zone drying (PRD) is an irrigation strategy that applies water to only one part of the root zone, whereas the other part is not watered so is under water stress conditions (English et al., 1990). PRD has improved yield (Dodd, 2009; Kang et al., 2001; Sepaskhah and Ahmadi, 2010; Shao et al., 2010) and water use efficiency (Davies et al., 2002) compared with full irrigation at the same water level. Compared with full irrigation, PRD reduced water consumption by $30 \%$ to $50 \%$

Received for publication 28 Feb. 2013. Accepted for publication 8 July 2013. We are grateful for the research funds that are provided by National Natural Science Foundation of China (30370986). We thank Dr. Douglas D. Archbold and Junhua Li for manuscript revision.

${ }^{1}$ Corresponding author. E-mail: shhli@wbgcas.cn. without significant yield reduction (Liu et al., 2006b; Sepaskhah and Ahmadi, 2010). Roots were partially water stressed under PRD, which could affect photosynthesis. Studies on potato [Solanum tuberosum (Liu et al., 2006a)], hot pepper [Capsicum annuum (Shao et al., 2010)], and maize [Zea mays (Kirda et al., 2005)] have shown that $P_{n}$ was significantly reduced. The photosynthetic mechanisms that are associated with the performance of PRD plants with more efficient use of water resources are still unclear. Thus, studies on the response of plant photosynthesis under PRD conditions, especially the difference of photosynthesis between PRD and whole root water stress, are needed. The findings may be applicable to the design of more efficient irrigation strategies with limited negative impact on crop yield.

Regarding the effects of PRD, little is known about how $\mathrm{P}_{\mathrm{n}}$ is limited and whether there are changes in energy fluxes in the photosynthetic apparatus. The status of the photosynthetic apparatus may be investigated in vivo using fast chlorophyll a fluorescence transient analysis (Strasser and Tsimilli-Michael, 2001). The transient parameters are reliable indicators of the status of the donor and acceptor sides of photosystem II (PSII) reaction centers (RCs). Changes of the energy fluxes in the photosynthetic apparatus including trapped photons, trapped excitons, transported electrons, and dissipated energy can also 
be indicated by the transient parameters (Strasser and TsimilliMichael, 2001).

The decrease in photosynthesis of plant leaves under water stress causes inefficient use of light energy. Consequently, light energy can become excessive in the chloroplast (Long et al., 1994). As water stress proceeds, excessive light energy may result in photoinhibition and serious damage (Long et al., 1994; Quick et al., 1992). There are many ways for leaves to dissipate excess light energy such as non-photochemical quenching, photorespiration, and Mehler peroxidase reactions (Asada, 1999; Chen et al., 2004a; Dai et al., 2004; Jiang et al., 2006; Noctor et al., 2002). Non-photochemical quenching increased in PRD-treated hot pepper compared with full irrigation (Shao et al., 2010). The dissipation of xanthophyll pigments in the photosynthetic structure prevented the damage of excess light to PSII (Niyogi, 2000; Ort, 2001). Through the de-epoxidation of the xanthophyll cycle pigments and the formation of zeaxanthin (Z), excess absorbed energy was harmlessly dissipated as heat (Horton et al., 1994). Few studies have been conducted on the xanthophyll cycle-dependent thermal energy dissipation under PRD conditions compared with whole root zone drying or with well-watered plants.

In this study, whole and partial root zone drying were simulated by using polyethylene glycol 6000 (PEG6000) stressed young micropropagated apple trees. The objective of this study was to investigate water stress effects including PRD on photosynthetic performance, especially focused on the PSII $\mathrm{RCs}$ and energy partitioning in leaves.

\section{Materials and Methods}

Materials. One-year-old micropropagated 'Royal Gala' apple trees were used in this study. The trees were $\approx 30 \mathrm{~cm}$ high with uniform vegetative growth. The trees were transferred from soil and precultured hydroponically in black glass containers $[60 \times 18 \times 11 \mathrm{~cm}$ (length $\times$ width $\times$ height $)]$ in halfstrength Hoagland nutrient solution for $6 \mathrm{~d}$, which was then replaced by full-strength nutrient solution. The solution was completely changed every other day throughout the study. The culture solution was evenly aerated with three containers sharing an air pump, which emitted air at $70 \mathrm{~L} \cdot \mathrm{min}^{-1}$. Water was added daily to the containers to counterbalance water loss through transpiration. The containers were equally divided into two separate compartments by a glass plate ( $8 \mathrm{~cm}$ height). When trees were transferred to the containers, the roots were equally divided between the two compartments. To prevent solution exchange between the two compartments through the root crown, a lanolin barrier was used at the base of the trunk. The compartments were covered by a wood board with shadecloth to prevent exposure of roots to light. Trees were grown in a greenhouse under natural light with average air temperatures ranging from a low of $20^{\circ} \mathrm{C}$ at night to a high of $38^{\circ} \mathrm{C}$ during the day during the study.

TreatMents. HRS and WRS were started at 0700 HR on Day 1 of water stress by adding PEG6000 $(18 \% \mathrm{w} / \mathrm{v})$ to the nutrient solution (Hsiao, 1973). The roots of control trees (CK) were cultured using only nutrient solution. Each of the water stress treatments and the $\mathrm{CK}$ were replicated six times in a randomized complete block design with seven plants in each replicate. Predawn leaf water potential was measured using a Scholander pressure chamber (ZIZ-4; Lanzhou University, Lanzhou, China) on leaves removed from the upper part of trees.
Measurement of gas exchange and Chlorophyll fluoRESCENCE. Mature leaves from the upper part of six trees per treatment were selected for measurements of gas exchange and chlorophyll fluorescence. Gas exchange was measured everyday with a portable photosynthesis system (LI-6400; LI-COR, Lincoln, NE) $\approx 0930 \mathrm{HR}$ under natural sunlight and at $25 \pm 2{ }^{\circ} \mathrm{C}$ throughout the experiment. Diurnal changes of $\mathrm{P}_{\mathrm{n}}$ were measured every $1.5 \mathrm{~h}$ from 0700 to 1730 HR on Days 3 and 6 after initiating water stress. $\mathrm{Ci}$ and $g_{\mathrm{S}}$ were obtained when $\mathrm{P}_{\mathrm{n}}$ was measured. All measurements were performed at ambient $\mathrm{CO}_{2}$ $\left(380 \pm 15 \mu \mathrm{mol} \cdot \mathrm{mol}^{-1}\right)$ and relative humidity of $75 \% \pm 5 \%$.

Modulated chlorophyll fluorescence parameters were measured diurnally as with gas exchange measurements using a portable fluorescence monitoring system (FMS-2; Hansatech, King's Lynn, U.K.). Maximal fluorescence in the dark-adapted state $\left(\mathrm{Fm}^{\circ}\right)$ and the light-adapted state (Fm') were measured after a pulse of saturating light. $\mathrm{Fm}^{\circ}$ was measured on leaves at predawn when leaves were fully dark-adapted and nonstressed on the first day after initiating water stress (Maxwell and Johnson, 2000). Fm' was measured during the day under natural sunlight. The steady-state fluorescence during exposure to natural illumination (Fs) and minimum chlorophyll fluorescence of PSII during illumination (Fo') were also measured. The following calculations were made: 1) the maximal efficiency of PSII photochemistry in the light-adapted state, Fv'/Fm' = (Fm' - Fo')/Fm' (Kitajima and Butler, 1975); 2) the actual efficiency of PSII in the light-adapted state, $\Phi$ PSII $=\left(F{ }^{\prime}-\mathrm{Fs}\right) /$ Fm' (Genty et al., 1989); 3) the non-photochemical quenching, $\mathrm{NPQ}=\left(\mathrm{Fm}^{\circ} / \mathrm{Fm}^{\prime}\right)-1$ (Bilger and Björkman, 1990; Duan et al., 2008).

The kinetic transient fluorescence shows a polyphasic fluorescence rise consisting of a sequence of phases, denoted as O, J, I, and P [OJIP test (Strasser and Tsimilli-Michael, 2001)]. In our study, OJIP measurements were taken at $\approx 0930 \mathrm{HR}$ everyday using a chlorophyll meter (Handy-PEA ${ }^{\circledR}$; Hansatech) (Luo et al., 2011) on the same leaves as photosynthetic measurements after a dark adaptation period of more than $20 \mathrm{~min}$. The fluorescence signals were recorded within a timespan from $10 \mu \mathrm{s}$ to $1 \mathrm{~s}$ with a data acquisition rate of $10 \mu \mathrm{s}$ for the first $2 \mathrm{~ms}$, which produces OJIP transient parameters containing a significant amount of complex information. The information is associated with the energy cascade from light absorption to electron transport in photosynthesis (Strasser and Strasser, 1995). In the energy cascade, antenna pigments absorb the energy of photon quanta. The majority of energy is trapped in the form of excitons by the active RCs and then transformed to reducing energy. Subsequently, electrons are transported and used in carbon fixation or other ways. The minority of energy is dissipated in the form of fluorescence or heat.

Original data include fluorescence intensity at $50 \mu \mathrm{s}$ [O step (the minimum intensity Fo)], fluorescence intensity at $300 \mu \mathrm{s}$ [K step (Fk)], fluorescence intensity at $2 \mathrm{~ms}$ [J step (Fj)], fluorescence intensity at $30 \mathrm{~ms}$ [I step (Fi)], and peak fluorescence intensity [Fp (the maximum intensity Fm)] (Christen et al., 2007; Li et al., 2005; Strasser and Tsimilli-Michael, 2001). The maximum variable fluorescence intensity $(\mathrm{Fv}=\mathrm{Fm}-\mathrm{Fo})$ was obtained. The yield indices or flux ratios derived from the energy flux theory (Strasser and Strasser, 1995) include maximum quantum yield of primary photochemistry $(\mathrm{Fv} / \mathrm{Fm})$, conformation term for the primary photochemistry (Fv/Fo), the probability that a trapped exciton moves an electron further than $\mathrm{Q}_{\mathrm{A}}^{-}\left[\psi_{0}=1-(\mathrm{Fj}-\mathrm{Fo}) /(\mathrm{Fm}-\mathrm{Fo})\right]$, the probability that 
an absorbed photon moves an electron further than $\mathrm{Q}_{\mathrm{A}}^{-}\left(\varphi \mathrm{E}_{0}=\right.$ $\left.\mathrm{ET}_{0} / \mathrm{ABS}=\mathrm{Fv} / \mathrm{Fm} \cdot \psi_{0}\right)$, and maximum quantum yield of nonphotochemical de-excitation $\left(\varphi \mathrm{D}_{0}=\mathrm{Fo} / \mathrm{Fm}\right)$. The slope at the origin of the normalized fluorescence rise $\left[\mathrm{M}_{0}=4(\mathrm{Fk}-\mathrm{Fo}) /\right.$ $(\mathrm{Fm}-\mathrm{Fo})]$, relative variable fluorescence at $2 \mathrm{~ms}$ or $30 \mathrm{~ms}[\mathrm{Vt}=$ $(\mathrm{Ft}-\mathrm{Fo}) /(\mathrm{Fm}-\mathrm{Fo})]$, the ratio of variable fluorescence to the amplitude $\mathrm{Fj}$-Fo at the $\mathrm{K}$-step $[\mathrm{Wk}=(\mathrm{Fk}-\mathrm{Fo}) /(\mathrm{Fj}-\mathrm{Fo})]$, normalized total complementary area above the OJIP transient reflecting sing-turnover $\mathrm{Q}_{\mathrm{A}}$ reduction events (equaling the pool size of electron carriers per RC of PSII) [Sm = Area/(Fm - Fo $)$, and turnover number of $\mathrm{Q}_{\mathrm{A}}$ reduction and re-oxidation $[\mathrm{N}=$ $\left.\mathrm{Sm} \cdot\left(\mathrm{M}_{0} / \mathrm{Vj}\right)\right]$ are normalized signals from the measured fluorescence transients. Quantum efficiencies in the energy cascade for the events of absorption, trapping, electron transport, and dissipation on a $\mathrm{RC}$ basis $\left[\mathrm{ABS} / \mathrm{RC}=\left(\mathrm{M}_{0} / \mathrm{Vj}\right) /(\mathrm{Fv} / \mathrm{Fm})\right.$, $\mathrm{TR}_{0} / \mathrm{RC}=\mathrm{M}_{0} / \mathrm{Vj}, \mathrm{ET}_{0} / \mathrm{RC}=\mathrm{M}_{0} / \mathrm{Vj} \cdot \psi_{0}, \mathrm{DI}_{0} / \mathrm{RC}=(\mathrm{ABS} / \mathrm{RC})-$ $\left.\left(\mathrm{TR}_{0} / \mathrm{RC}\right)\right]$ were calculated as well as quantum efficiencies on an active cross-section of the leaf tissue basis at time zero $\left(\mathrm{CS}_{0}\right)\left[\mathrm{ABS} / \mathrm{CS}_{0} \approx \mathrm{Fo}, \mathrm{TR}_{0} / \mathrm{CS}_{0}=\mathrm{TR}_{0} / \mathrm{ABS} \cdot\left(\mathrm{ABS} / \mathrm{CS}_{0}\right)\right.$, $\mathrm{ET}_{0} / \mathrm{CS}_{0}=\mathrm{ET}_{0} / \mathrm{ABS} \cdot\left(\mathrm{ABS} / \mathrm{CS}_{0}\right), \mathrm{DI}_{0} / \mathrm{CS}_{0}=\left(\mathrm{ABS} / \mathrm{CS}_{0}\right)-$ $\left.\left(\mathrm{TR}_{0} / \mathrm{CS}_{0}\right)\right]$. The performance indices were biophysical expression parameters: 1) performance index on an absorption basis was $\left\{\mathrm{PI}_{\mathrm{ABS}}=\left(\mathrm{Vj} / \mathrm{M}_{0}\right) \cdot(\mathrm{Fv} / \mathrm{Fm}) \cdot(\mathrm{Fv} / \mathrm{Fo}) \cdot\left[\psi_{0} /\left(1-\psi_{0}\right)\right]\right\}$; and 2) performance index on a CS basis at time zero was $\left(\mathrm{PI}_{\mathrm{CS} 0}=\mathrm{Fo} \cdot \mathrm{PI}_{\mathrm{ABS}}\right)$. For terms and formulae of the OJIP parameters (Christen et al., 2007; Li et al., 2005; Strasser and Tsimilli-Michael, 2001) (see also Table 1). The values of OJIP test parameters are normalized using the formula $\left(\mathrm{F}_{\text {treatment }}-\mathrm{F}_{\mathrm{ck}}\right) / \mathrm{F}_{\mathrm{ck}}$, where $F_{\text {treatment }}$ is the parameter value of the treated tree and $F_{c k}$ is the value of the CK tree. The control data are normalized to 0 . A positive normalized value means an increase of the parameter in water stress-treated trees compared with the CK, whereas a negative normalized value means a reduction.

Pigment analysis. Frozen leaf samples were extracted in ice-cold $100 \%$ acetone, and the pigment extracts were filtered through a $0.45-\mu \mathrm{m}$ membrane filter. Pigments were analyzed using a high-performance liquid chromatography system (P680; Dionex, Sunnyvale, CA) according to procedures previously described (Thayer and Björkman, 1990). The xanthophyll cycle involves the de-epoxidation of violaxanthin (V) to $\mathrm{Z}$ through antheranxanthin (A) and re-expoxidation of $\mathrm{Z}$ to $\mathrm{V}$ through $\mathrm{A}$. The amounts of $\mathrm{A}, \mathrm{V}$, and $\mathrm{Z}$ were obtained through conversion of peak areas from leaf extracts according to pure standards. The DEPS was calculated as DEPS $=(0.5 \mathrm{~A}+\mathrm{Z}) /(\mathrm{Z}+\mathrm{A}+\mathrm{V})$ (Pieters et al., 2003).

Statistical ANALYSIS. A randomized complete block design was used in this study. The data in the graphs were subjected to analysis of variance and means were compared by Duncan's new multiple range test at $P<0.05$. All analyses were calculated with SPSS software (Version 13.0; IBM Corp., Armonk, NY).

Table 1. Terms and formulae used in the analysis of the fast chlorophyll a fluorescence.

\begin{tabular}{|c|c|}
\hline Term and formulae & Definition \\
\hline $\mathrm{Fm}=\mathrm{Fp}$ & $\begin{array}{l}\text { Maximum fluorescence, when all photosystem II (PSII) reaction centers (RCs) } \\
\text { are closed }\end{array}$ \\
\hline $\mathrm{Fv}=\mathrm{Fm}-\mathrm{Fo}$ & Maximum variable fluorescence \\
\hline $\mathrm{Wk}=(\mathrm{Fk}-\mathrm{Fo}) /(\mathrm{Fj}-\mathrm{Fo})$ & Ratio of variable fluorescence to the amplitude $\mathrm{Fj}-\mathrm{Fo}$ at the $\mathrm{K}$-step \\
\hline $\mathrm{M}_{0}=4(\mathrm{Fk}-\mathrm{Fo}) /(\mathrm{Fm}-\mathrm{Fo})$ & Slope at the origin of the normalized fluorescence rise \\
\hline Area & Total complementary area between fluorescence induction curve and $\mathrm{F}=\mathrm{Fm}$ \\
\hline $\mathrm{Sm}=\mathrm{Area} /(\mathrm{Fm}-\mathrm{Fo})$ & $\begin{array}{l}\text { Normalized Area reflecting sing-turnover } \mathrm{Q}_{\mathrm{A}} \text { reduction events } \\
\text { (= pool size of electron carriers per RC of PSII) }\end{array}$ \\
\hline $\mathrm{N}=\mathrm{Sm} \cdot\left(\mathrm{M}_{0} / \mathrm{Vj}\right)$ & Turnover number of $\mathrm{Q}_{\mathrm{A}}$ reduction and re-oxidation \\
\hline \multicolumn{2}{|l|}{ The yield indices or flux ratios } \\
\hline$\varphi \mathrm{E}_{0}=\mathrm{ET}_{0} / \mathrm{ABS}=\mathrm{Fv} / \mathrm{Fm} \cdot \psi_{0}$ & Probability that an absorbed photon moves an electron further than $\mathrm{Q}_{\mathrm{A}}^{-}$ \\
\hline$\varphi \mathrm{D}_{0}=\mathrm{Fo} / \mathrm{Fm}$ & Maximum quantum yield of non photochemical de-excitation \\
\hline \multicolumn{2}{|c|}{ Quantum efficiencies (phenomenological energy fluxes per RC or per active cross section of the leaf tissue-CS) } \\
\hline $\mathrm{ABS} / \mathrm{RC}=\left(\mathrm{M}_{0} / \mathrm{Vj}\right) /(\mathrm{Fv} / \mathrm{Fm})$ & Absorption flux per RC (at $\mathrm{t}=0$ ) \\
\hline $\mathrm{TR}_{0} / \mathrm{RC}=\mathrm{M}_{0} / \mathrm{Vj}$ & Trapped energy flux per RC (at $t=0$ ) \\
\hline $\mathrm{ET}_{0} / \mathrm{RC}=\mathrm{M}_{0} / \mathrm{Vj} \cdot \psi_{0}$ & Electron transport flux per $\mathrm{RC}($ at $\mathrm{t}=0$ ) \\
\hline $\mathrm{DI}_{0} / \mathrm{RC}=(\mathrm{ABS} / \mathrm{RC})-\left(\mathrm{TR}_{0} / \mathrm{RC}\right)$ & Dissipated energy flux per RC (at $t=0$ ) \\
\hline $\mathrm{ABS} / \mathrm{CS}_{0} \approx \mathrm{Fo}$ & Absorption flux per CS, approximated by Fo \\
\hline $\mathrm{TR}_{0} / \mathrm{CS}_{0}=\mathrm{TR}_{0} / \mathrm{ABS} \cdot\left(\mathrm{ABS} / \mathrm{CS}_{0}\right)$ & Trapped energy flux per CS $($ at $t=0)$ \\
\hline $\mathrm{EI}_{0} / \mathrm{CS}_{0}=\mathrm{ET}_{0} / \mathrm{ABS} \cdot\left(\mathrm{ABS} / \mathrm{CS}_{0}\right)$ & Electron transport flux per $\mathrm{CS}($ at $\mathrm{t}=0$ ) \\
\hline
\end{tabular}




\section{Results}

Predawn leaf water potential. To investigate the extent of water stress induced by the treatments, predawn leaf water potentials were measured. WRS treatment affected predawn leaf water potentials compared with $\mathrm{CK}$ and HRS trees from Day 2 after initiating water stress (Fig. 1A), indicating that water stress treatments in this study were effective. Predawn leaf water potentials in CK and HRS trees remained stable at -0.3 to $-0.1 \mathrm{MPa}$ throughout the experiment. However, predawn levels were reduced by WRS, dropping to less than $-0.8 \mathrm{MPa}$ on Day 2 after initiating water stress and staying between -1.1 and $-0.8 \mathrm{MPa}$ thereafter during the water stress period (Fig. 1A).

Gas exchange Parameters. Daily changes of photosynthetic parameters $\approx 0930 \mathrm{HR}$ were representative of the effects of water treatments on photosynthesis as stress progressed (Fig. 1B-D). Before the initiation of the PEG-induced water stress, all trees had the similar $\mathrm{P}_{\mathrm{n}}$ [Fig. 1B (Day 0)]. Starting at Day 1 of water stress, $P_{n}$ of WRS and HRS leaves decreased and remained low compared with $C K$ leaves. In CK leaves, $P_{n}$ was high although there was some variation resulting from variable daily natural irradiance (Fig. 1B). The effects of HRS (Fig. 1B-D); for example, $\mathrm{P}_{\mathrm{n}}$ in HRS and WRS was $48.3 \%$ to $81.9 \%$ and $21.2 \%$ to $52.7 \%$ of CK, respectively. Regarding $\mathrm{Ci}$, it decreased in WRS on Days 2 and 3 after initiating water stress compared with $\mathrm{CK}$, but it significantly increased at the end of the experiment. $\mathrm{Ci}$ of HRS was either similar to or at a lower level than CK (Fig. 1D).

In this study, we choose the diurnal changes on Days 3 and 6 after initiating water stress to represent the responses of gas exchange in the early and late periods of water stress (Fig. 2A-F). Regarding Ci on Day 3 of water stress, it decreased in WRS leaves with the exception of an increase at $\approx 1200$ HR compared on leaf $\mathrm{P}_{\mathrm{n}}, g_{\mathrm{S}}$, and $\mathrm{Ci}$ were much less obvious than that of WRS

with CK (Fig. 2C). On Day 6, Ci in WRS leaves was generally higher than in $\mathrm{CK}$ leaves (Fig. 2F). The $\mathrm{Ci}$ in HRS leaves was lower than in CK leaves before and after 1200 HR on Day 3 (Fig. 2C). However, the HRS value was generally similar to the CK on Day 6 (Fig. 2F). Different from Ci, diurnal $P_{n}$ and $g_{S}$ in HRS leaves decreased significantly compared with those in CK leaves, although the reduction in WRS leaves was greater (Figs. 2A-B and 2D-E).

RESPONSE OF MODULATED CHLOROPHYLL FLUORESCENCE. The influence of water stress on modulated chlorophyll parameters, including Fv'/Fm', ФPSII, and NPQ, was not obvious until Day 6 after initiating water stress (data not shown). Few differences were observed between HRS and CK leaves (Fig. 2G-I). In HRS leaves, Fv'/Fm' and NPQ were similar to CK except at $1400 \mathrm{HR}$ and $1600 \mathrm{HR}$; Fv'/Fm' decreased 26.9\% and NPQ was 1.39 times higher compared with CK. There were no differences between HRS and CK leaves regarding $\Phi$ PSII. In WRS leaves, Fv'/Fm' and $\Phi$ PSII were reduced by $19.7 \%$ and $37.4 \%$, respectively, compared with CK leaves (Fig. 2G-H). Moreover, NPQ of WRS leaves (except $1130 \mathrm{HR}$ ) increased significantly and was $\approx 1.5$ times higher than in CK leaves (Fig. 2I).

OJIP PARAMETERS. A multiparametric plot with the normalization of some selected OJIP test parameters (normalized to $\mathrm{CK}$ ) allows an accurate expression of water stress conditions (Fig. 3). Analysis of all of the transients can contribute to an understanding of the response of photosynthesis to HRS and WRS. OJIP parameters were similar among water-stressed and CK leaves until Day 3 after initiating water stress. As water stress progressed, differences were more evident between treatments and CK with OJIP parameters of WRS leaves changing more than those of HRS leaves compared with $\mathrm{CK}$ leaves on Day 6 (Fig. 3).

Minimum and maximum fluorescence (Fo and Fm) in HRS were similar to CK leaves throughout the experiment (Fig. 3). However, slight changes of Fo and Fm were observed under WRS on
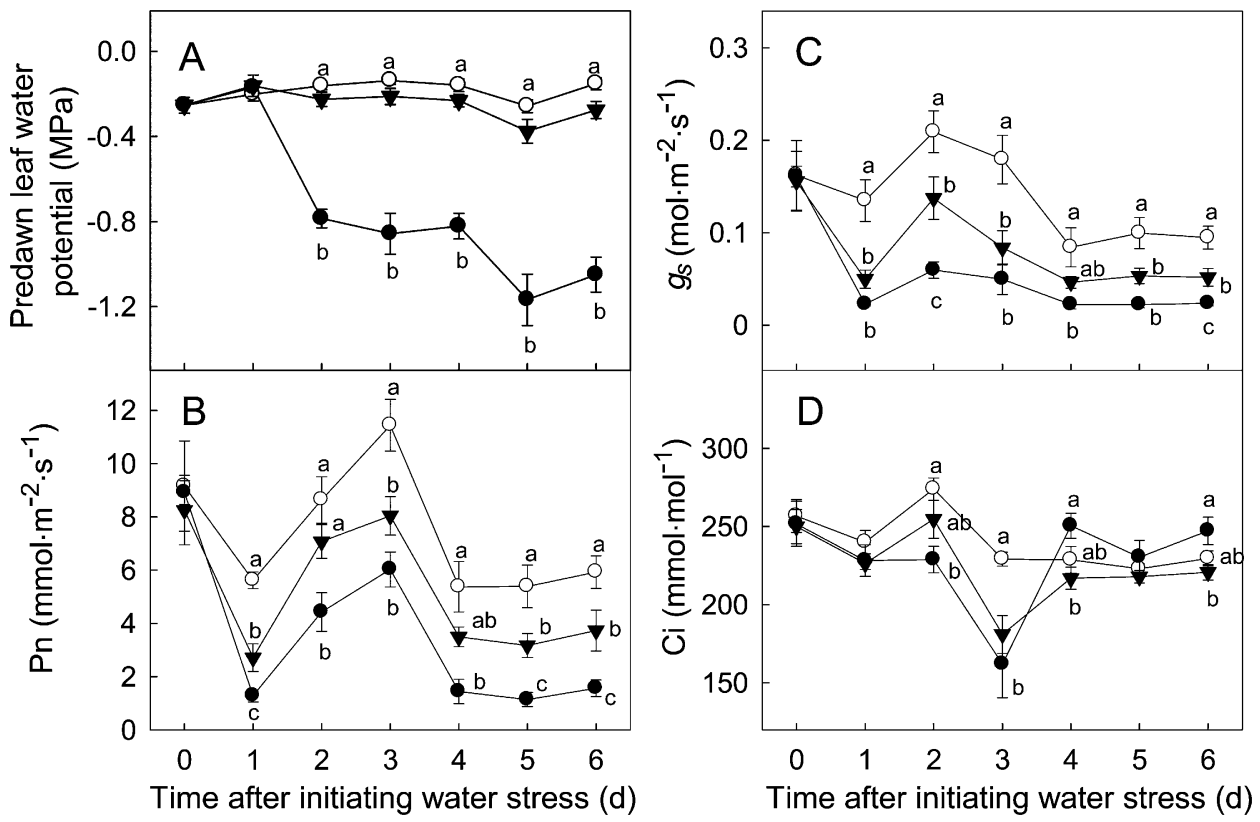

Fig. 1. Changes in (A) predawn leaf water potential, $(\mathbf{B})$ net photosynthetic rate $\left(\mathrm{P}_{\mathrm{n}}\right),(\mathbf{C})$ stomatal conductance $\left(g_{\mathrm{S}}\right)$, and $(\mathbf{D})$ intercellular $\mathrm{CO}_{2}$ concentration $(\mathrm{Ci})$ of leaves of micropropagated apple trees in response to halfroot water stress $(\boldsymbol{\nabla})$ and whole-root water stress $(\boldsymbol{O})$ compared with control trees without water stress $(\bigcirc)$. The vertical bar represents \pm SE of the mean of six replicates. Different letters indicate significant differences among treatments at each day at $P<0.05$ based on Duncan's new multiple range test.
Day 3 compared with CK with more differences during the late stress period (data on Days 4 and 5 were not shown). For example, Fo increased $25 \%$ and Fm decreased $24.8 \%$, respectively, in WRS compared with CK on Day 6 (Fig. 3B). The changes of Fo and Fm led to reductions of $39.4 \%, 21.6 \%$, and $48.7 \%$, respectively, in $\mathrm{Fv}, \mathrm{Fv} / \mathrm{Fm}$, and $\mathrm{Fv} / \mathrm{Fo}$ and an increase of $72.9 \%$ in $\varphi D_{0}\left(\varphi D_{0}=F o / F m\right)$ in WRS leaves compared with CK (Fig. 3B). Moreover, Fv/Fo decreased and $\varphi \mathrm{D}_{0}$ increased from Day 3 after initiating water stress in WRS compared with CK (Fig. 3).

HRS or WRS had no or little effect on the ratio of variable fluorescence to the amplitude $\mathrm{Fj}-\mathrm{Fo}$ at the K-step (Wk), which is an indicator of the donor side of PSII RCs (Fig. 3). Only a slight change of $5.2 \%$ was observed in WRS leaves at the end of the experiment compared with CK. Regarding indicators 

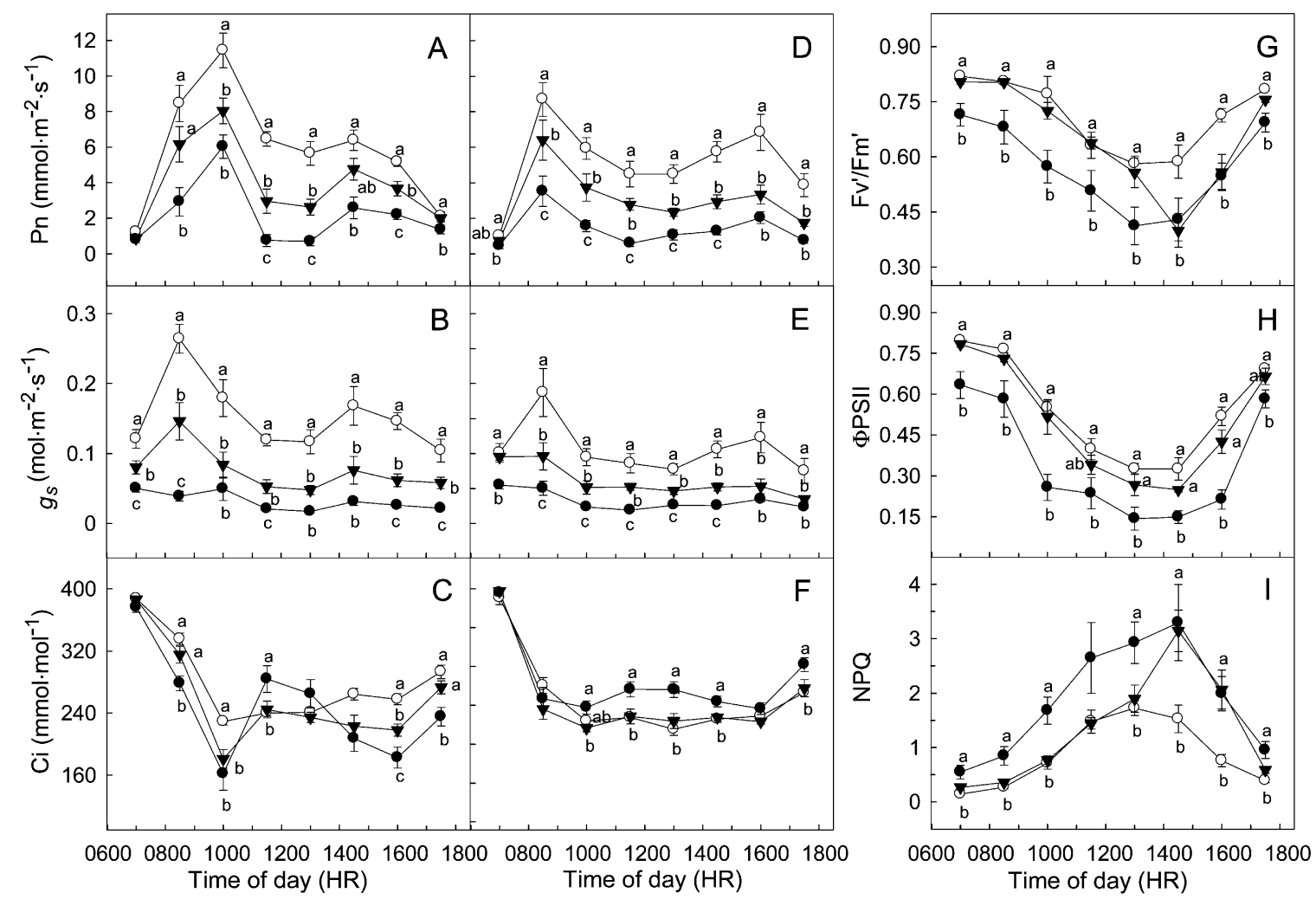

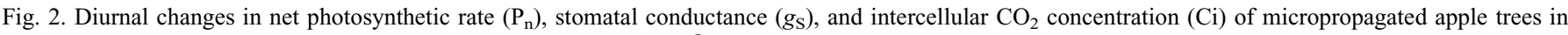
response to half-root water stress $(\boldsymbol{\nabla})$ and whole-root water stress $(\mathbf{O})$ compared with trees without water stress $(\bigcirc)$ on Day $3(\mathbf{A}-\mathbf{C})$ and Day $6(\mathbf{D}-\mathbf{F})$ after initiating water stress. In G-I, diurnal variations in (G) the maximal efficiency of photosystem II (PSII) photochemistry in the light-adapted state (Fv'/Fm'), (H) the actual efficiency of PSII in the light-adapted state (ФPSII), and (I) non-photochemical quenching (NPQ) were investigated. The vertical bar represents \pm SE of the mean of six replicates. Different letters indicate significant differences among treatments at the same time point at $P<0.05$ based on Duncan's new multiple range test.

related to the acceptor side of PSII RCs, no or only slight changes $(2.8 \%$ to $8.5 \%)$ were observed in HRS plants. Relative variable fluorescence at $2 \mathrm{~ms}(\mathrm{Vj})$, the slope at the origin of the normalized fluorescence rise $\left(\mathrm{M}_{0}\right)$, the probability that an absorbed photon moves an electron further than $\mathrm{Q}_{\mathrm{A}}{ }^{-}\left(\varphi \mathrm{E}_{0}\right)$ and that a trapped exciton moves an electron further than $\mathrm{Q}_{\mathrm{A}}{ }^{-}\left(\psi_{0}\right)$, was very sensitive and responded early to WRS (Fig. 3A). Their values changed $15.7 \%$ to $23.9 \%$ under WRS during the early period (data not shown) and more $(27.0 \%$ to $41.4 \%)$ during the late period of water stress compared with CK (data not shown). Besides, relative variable fluorescence at $30 \mathrm{~ms}$ (Vi), the pool size of the electron carriers per RC of PSII (Sm), and turnover number of $\mathrm{Q}_{\mathrm{A}}$ reduction and re-oxidation $(\mathrm{N})$ changed $15.2 \%, 8.3 \%$, and $12.4 \%$, respectively, under WRS compared with CK at the end of the study (Fig. 3B).

PSII energy fluxes were studied in CK, HRS, and WRS plants. HRS had no obvious effects on energy absorbed, trapped, used for electron transport, or dissipated per PSII RC compared with CK (Fig. 3). There were no differences in PSII energy fluxes between WRS and CK leaves on Day 3 (Fig. 3A). However, as water stress progressed, the energy flux used for electron transport per $\mathrm{RC}\left(\mathrm{ET}_{0} / \mathrm{RC}\right)$ and dissipation energy flux per $\mathrm{RC}\left(\mathrm{DI}_{0} / \mathrm{RC}\right)$ reduced $30.4 \%$ and increased $122.5 \%$, respectively, under WRS on Day 6 compared with CK (Fig. 3B). In addition, absorption energy flux per $\mathrm{RC}(\mathrm{ABS} / \mathrm{RC})$ increased $24.0 \%$, but trapped energy flux per $\mathrm{RC}$ at time zero $\left(\mathrm{TR}_{0} / \mathrm{RC}\right)$ did not change in WRS compared with CK leaves (Fig. 3).
HRS did not affect the energy absorbed, trapped, used for electron transport, or dissipated per CS of leaf tissue, except that dissipated energy flux per CS at time zero $\left(\mathrm{DI}_{0} / \mathrm{CS}_{0}\right)$ increased $17.7 \%$ compared with CK on Day 6 (Fig. 3B). $\mathrm{DI}_{0} / \mathrm{CS}_{0}$ responded early in WRS plants with an increase of $15.5 \%$ compared with CK on Day 3 (Fig. 3A). As water stress progressed, $\mathrm{DI}_{0} / \mathrm{CS}_{0}$ under WRS increased $121.9 \%$ and energy flux used for electron transport per CS at time zero $\left(\mathrm{ET}_{0} / \mathrm{CS}_{0}\right)$ declined $29.5 \%$ compared with $\mathrm{CK}$ values (Fig. 3B). No differences were observed on trapped energy flux per CS at time zero $\left(\mathrm{TR}_{0} / \mathrm{CS}_{0}\right)$ between WRS and CK.

The photochemical performance was examined using two indices. The photosynthetic performance index on an absorption basis $\left(\mathrm{PI}_{\mathrm{ABS}}\right)$ and performance index on a $\mathrm{CS}$ basis at time zero (PIcso) in HRS were similar to CK leaves on Day 3 (Fig. 3A). However, they decreased under WRS from Day 3 after initiating water stress with a reduction of $29.9 \%$ and $28.1 \%$, respectively, compared with CK (Fig. 3A). As water stress was prolonged, WRS affected $\mathrm{PI}_{\mathrm{ABS}}$ and PIcso more evidently with a reduction of $67.9 \%$ and $65.3 \%$, respectively, compared with $\mathrm{CK}$, whereas HRS only led to a decrease of $21.3 \%$ and $16.7 \%$, respectively, at the end of water stress (Fig. 3).

DEPS. An obvious stress effect on DEPS was detected in WRS leaves compared with HRS and CK leaves from Day 2 (Fig. 4). DEPS, expressed as [(0.5A+Z)/ $(\mathrm{V}+\mathrm{A}+\mathrm{Z})]$, in CK and HRS leaves remained at $\approx 0.1$ throughout the experiment, whereas that of WRS leaves significantly increased. However, 

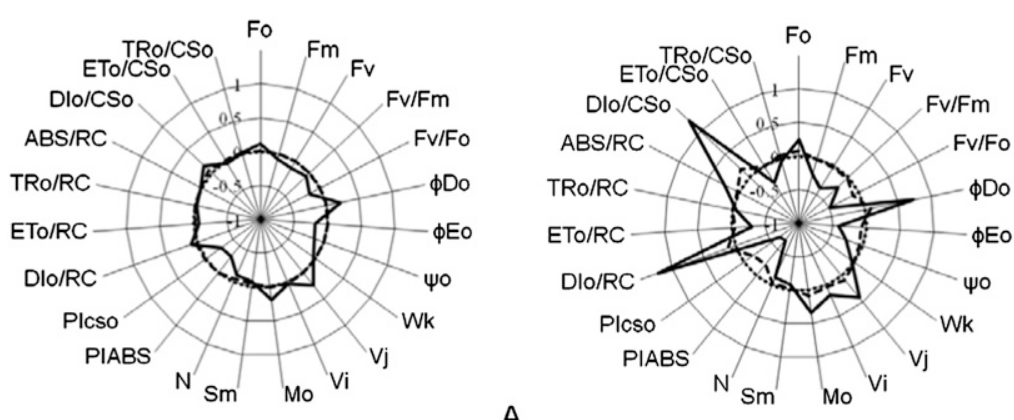

A

Fig. 3. Influence of whole-root water stress (solid line) and half-root water stress (dashed line) on selected fast chlorophyll a fluorescence (i.e., OJIP test) parameters of leaves of micropropagated apple trees at $\approx 0930 \mathrm{HR}$ on Day 3 (A) and Day 6 (B) after initiating water stress compared with control trees without water stress $(\mathrm{CK}$, dotted circle $=0)$. The data plotted (plot center $=-1$, maximum $=1.49)$ are OJIP parameters normalized by formulae: $\left(F_{\text {treatment }}-F_{c k}\right) / F_{c k}$, where $F_{\text {treatment }}$ and $\mathrm{F}_{\mathrm{ck}}$ represent the parameter values of the water stress-treated and $\mathrm{CK}$ plants, respectively. Values of CK plants were normalized to 0 . Fo and Fm are minimum and maximum fluorescence, respectively. Fk, Fj, and Fi are fluorescence intensities at $300 \mu \mathrm{s}, 2 \mathrm{~ms}$, and $30 \mathrm{~ms}$, respectively. Fv is maximum variable fluorescence $(\mathrm{Fv}=\mathrm{Fm}-\mathrm{Fo})$. Indicators related to status of photosystem II reaction centers (RCs) include: ratio of variable fluorescence to the amplitude Fj-Fo at the K-step (Wk), slope at the origin of the normalized fluorescence rise $\left[\mathrm{M}_{0}=4(\mathrm{Fk}-\mathrm{Fo}) /(\mathrm{Fm}-\mathrm{Fo})\right]$, relative variable fluorescence at 2 and $30 \mathrm{~ms}[\mathrm{Vj}$ and $\mathrm{Vi}$ are calculated according to $\mathrm{Vt}=(\mathrm{Ft}-\mathrm{Fo}) /(\mathrm{Fm}-\mathrm{Fo})]$, normalized total complementary area above the OJIP transient $[\mathrm{Sm}=\mathrm{Area} /(\mathrm{Fm}-\mathrm{Fo})]$, turnover number of $\mathrm{Q}_{\mathrm{A}}$ reduction and re-oxidation $\left[\mathrm{N}=\mathrm{Sm} \cdot\left(\mathrm{M}_{0} / \mathrm{Vj}\right)\right]$. Yield indices include: maximum quantum yield of primary photochemistry $(\mathrm{Fv} / \mathrm{Fm})$, conformation term for the primary photochemistry $(\mathrm{Fv} / \mathrm{Fo})$, probability that a trapped exciton moves an electron further than $\mathrm{Q}_{\mathrm{A}}^{-}\left(\psi_{0}=1-\mathrm{Vj}\right)$, probability that an absorbed photon moves an electron further than $\mathrm{Q}_{\mathrm{A}}^{-}\left(\varphi \mathrm{E}_{0}=\mathrm{Fv} / \mathrm{Fm} \cdot \psi_{0}\right)$, maximum quantum yield of non photochemical de-excitation $\left(\varphi D_{0}=F o / F m\right)$. Parameters relate to quantum efficiencies include: absorption flux per $\mathrm{RC}$ at $\mathrm{t}=0\left[\mathrm{ABS} / \mathrm{RC}=\left(\mathrm{M}_{0} / \mathrm{Vj}\right) /(\mathrm{Fv} / \mathrm{Fm})\right]$, trapped energy flux per $\mathrm{RC}$ at $\mathrm{t}=0\left(\mathrm{TR}_{0} / \mathrm{RC}=\mathrm{M}_{0} / \mathrm{Vj}\right)$, electron transport flux per $\mathrm{RC}$ at $\mathrm{t}=0\left(\mathrm{ET}_{0} / \mathrm{RC}=\mathrm{M}_{0} / \mathrm{Vj} \cdot \psi_{0}\right)$, dissipated energy flux per $\mathrm{RC}$ at $\mathrm{t}=0\left[\mathrm{DI}_{0} / \mathrm{RC}=(\mathrm{ABS} / \mathrm{RC})-\left(\mathrm{TR}_{0} / \mathrm{RC}\right)\right]$, trapped energy flux per active cross section of leaf tissue (CS) at $\mathrm{t}=0\left(\mathrm{TR}_{0} / \mathrm{CS}_{0}=\mathrm{Fv} / \mathrm{Fm} \cdot \mathrm{Fo}\right)$, electron transport flux per $\mathrm{CS}$ at $\mathrm{t}=0\left(\mathrm{EI}_{0} / \mathrm{CS}_{0}=\mathrm{M}_{0} / \mathrm{Vj} \cdot \psi_{0}\right)$, dissipated energy flux per CS at $\mathrm{t}=0\left[\mathrm{DI}_{0} / \mathrm{CS}_{0}=\left(\mathrm{ABS} / \mathrm{CS}_{0}\right)-\right.$ $\left.\left(\mathrm{TR}_{0} / \mathrm{CS}_{0}\right)\right]$. Performance indices include: performance index on absorption basis $\left\{\mathrm{PI}_{\mathrm{ABS}}=\right.$ $\left.\left(\mathrm{Vj} / \mathrm{M}_{0}\right) \cdot(\mathrm{Fv} / \mathrm{Fm})(\mathrm{Fv} / \mathrm{Fo}) \cdot\left[\psi_{0} /\left(1-\psi_{0}\right)\right]\right\}$, performance index on CS basis at $\mathrm{t}=0\left(\mathrm{PIcs}_{0}=\mathrm{Fo}_{0} \cdot \mathrm{PI}_{\mathrm{ABS}}\right)$. Each point represents the mean of six independent measurements.

there were no differences between HRS and CK leaves except for a slight increase in HRS leaves on Day 6 after initiating water stress.

\section{Discussion}

INFLUENCE OF HRS AND WRS ON GAS EXCHANGE PARAMETERS. Predawn leaf water potential (Fig. 1A) values indicates that WRS trees were under moderate water stress $(\mathrm{Li}$ and $\mathrm{Li}, 2005)$,

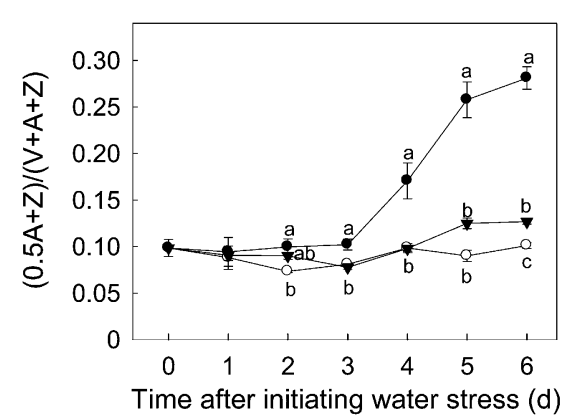

Fig. 4. De-epoxidization state of the xanthophyll cycle pigments $[(0.5 \mathrm{~A}+\mathrm{Z}) /$ $(\mathrm{V}+\mathrm{A}+\mathrm{Z})]$ in leaves of micropropagated apple trees without water stress $(\mathrm{O})$ under half-root water stress $(\boldsymbol{\nabla})$ and whole-root water stress $(\boldsymbol{O})$. Values are means of six replications; vertical bars indicate \pm SE. Different letters indicate significant differences among treatments at $P<0.05$ based on Duncan's new multiple range test. whereas in HRS trees, the watered roots met the need for water in maintenance of leaf water potential. The water-stressed roots may have produced abscisic acid and possibly reduced $g_{\mathrm{S}}$ (Stoll et al., 2000). WRS and HRS significantly decreased $P_{n}$ compared with CK plants, and the effect of WRS treatment was more significant (Figs. 1B, $2 \mathrm{~A}$, and 2D). Both HRS and WRS treatments reduced leaf $g_{\mathrm{S}}$ (Figs. 1C, 2B, and 2E) and leaf water loss by transpiration (data not shown). However, a greater rate of water extraction by the well-watered roots of the HRS trees may have occurred (Liu et al., 2006b), contributing to maintenance of leaf water potential (Fig. 1A). Decreased $g_{\mathrm{S}}$ in HRS leaves could explain their improved water use efficiency. The decrease of $P_{n}$ in higher plants may result from stomatal or non-stomatal limitations. When nonstomatal limitation of $\mathrm{P}_{\mathrm{n}}$ occurs, $\mathrm{Ci}$ increases in parallel with decreased $g_{\mathrm{S}}$ (Farquhar and Sharkey, 1982). HRS had a lower Ci than CK at 1000,1200 , and 1600 HR on Day 3, indicating that the decrease in $\mathrm{P}_{\mathrm{n}}$ may be mostly the result of stomatal limitation (Fig. 2C). WRS resulted in decreased $\mathrm{Ci}$ in the early period of water stress, but diurnal changes of $\mathrm{Ci}$ indicate that the reduction in $\mathrm{P}_{\mathrm{n}}$ by WRS was mainly the result of non-stomatal limitation during the later period such as that on Day 6 after water stress initiation (Fig. 2F). This might be the mechanism associated with the performance of HRS plants subjected to irrigation strategies with efficient use of water resources.

INFLUENCE OF HRS AND WRS ON CHLOROPHYLL PARAMETERS. The analysis of chlorophyll parameters indicated non-stomatal limitation in WRS leaves as time progressed. Differences in Fv'/Fm', ФPSII, and NPQ were observed in WRS leaves compared with CK and HRS leaves (Fig. 2G-I). The Fv'/Fm' and PPSII of WRS leaves were markedly lower than those of HRS and CK leaves. Compared with the CK, the lower values of Fv'/Fm' and ФPSII of WRS leaves at early morning and late afternoon indicate non-reversible photo damage in the PSII RCs in WRS (Fig. 2G-H). The NPQ of modulated chlorophyll parameters is often used as an indicator of mechanisms for preventing overexcitation of RCs (Ivanov and Edwards, 2000). To protect WRS leaves from damage by excess excitation energy, thermal dissipation of excitation energy in WRS leaves increased, as indicated by greater NPQ (Fig. 2I). NPQ increased in partially root-dried hot pepper compared with full irrigation (Shao et al., 2010). In this study, the Fv'/Fm' and NPQ values of HRS leaves were similar to CK except at 1400 and $1600 \mathrm{HR}$ (Figs. 2G and 2I) on Day 6. Moreover, there were no significant differences of $\Phi$ PSII between HRS and CK (Fig. 2H), indicating the PSII RCs were photoinhibited at 1400 and $1600 \mathrm{HR}$ on Day 6.

The decrease of $\mathrm{Fv} / \mathrm{Fm}$ is an important indicator of photoinhibition, whereas the increase of primary fluorescence Fo is one of the indicators of photoinhibition and photodamage (Kirilovsky et al., 1990). Compared with CK leaves, Fv/Fm of WRS leaves decreased and Fo increased markedly during the 
late period of water stress (Fig. 3B). It indicates that the integrity of the photosynthetic apparatus under WRS was affected as water stress progressed. Inhibition and damage to PSII RCs may include both donor and acceptor sides. The appearance of an additional " $\mathrm{K}$ " step expressed as Wk indicates damage to the oxygen-evolving complex at the donor side of PSII RCs (Srivastava et al., 1997). In this study, the value of Wk showed few changes under both WRS and HRS conditions. These results might indicate that the donor side of leaves was not influenced by water stress. However, $\mathrm{Vj}, \mathrm{Vi}, \mathrm{Sm}, \varphi \mathrm{Eo}, \psi$, $\mathrm{Mo}$, and $\mathrm{N}$, as indicators of the status of the acceptor side (Chen et al., 2004b; Li et al., 2005), significantly changed under WRS during the late period of the experiment, whereas they were little influenced by HRS (Fig. 3). These results indicate that the acceptor side of PSII in WRS leaves was markedly damaged compared with those in CK and in HRS leaves as water stress progressed.

The increase of $\mathrm{Vj}$ and $\mathrm{Vi}$ indicates inhibition of electron transport at the acceptor side of the PSII (Chen et al., 2004b; $\mathrm{Lu}$ and Zhang, 1999). The increase of $\mathrm{Vi}$ is used as a probe for an accumulation of $\mathrm{Q}_{\mathrm{B}}$ non-reducing PSII RCs as a result of an inability to transfer electrons from $\mathrm{Q}_{\mathrm{A}}{ }^{-}$to $\mathrm{Q}_{\mathrm{B}}$ (Lazár et al., 1997). When leaf photodamage happens, D1 protein in the PSII RCs degrades rapidly. Thus, the electron carriers, especially $\mathrm{Q}_{\mathrm{B}}$, are ready to be detached from the protein complex, which results in reduction of $\mathrm{Sm}$; i.e., the acceptor pool size of PSII RCs (Strasser et al., 1995). In this study, Sm in WRS slightly decreased during the late period of water stress as indicated by results on Day 6 (Fig. 3). This could result in a decrease of the probabilities that an absorbed photon and exciton moves an electron further than $\mathrm{Q}_{\mathrm{A}}^{-}(\varphi \mathrm{E} 0$ and $\psi 0)$ in PSII RCs of WRS leaves. Consequently, more light energy was used to reduce $\mathrm{Q}_{\mathrm{A}}$, resulting in an increase of $\mathrm{M}_{0}$; i.e., the relative rate of $\mathrm{Q}_{\mathrm{A}}$ reduction. In the meantime, the turnover numbers for $\mathrm{Q}_{\mathrm{A}}$ reduction and re-oxidized decreased, indicating decreased ability of $\mathrm{Q}_{\mathrm{A}}$ to transport electrons (Fig. 3).

The performance indices $\mathrm{PI}_{\mathrm{ABS}}$ and PIcso in the OJIP test (Fig. 3) are sensitive and suitable for the early detection of changes in photosystems as a result of water stress. Both WRS and HRS decreased performance indices as water stress progressed compared with CK (Fig. 3B). However, the influence of WRS was earlier and more serious. The decreases were mostly attributed to the reduction of $\mathrm{Fv} / \mathrm{Fm}$ and the probability that a trapped exciton moves an electron further than $\mathrm{Q}_{\mathrm{A}}^{-}\left(\psi_{0}\right)$. These changes could explain the sharp reduction of photosynthetic performance in WRS compared with HRS and CK leaves.

INFLUENCE OF HRS AND WRS ON EXCESS ENERGY DISSIPATION. WRS sharply decreased the light use efficiency of the photosystems, whereas the effects of HRS were very slight as water stress was prolonged. In the meantime, $\varphi \mathrm{D}_{0}, \mathrm{DI}_{0} / \mathrm{RC}, \mathrm{DI}_{0} / \mathrm{CS}$, and NPQ in WRS leaves increased, indicating increased excess energy dissipation compared with CK (Figs. 2I and 3B). NPQ is closely related to excitation energy and involves the protection process of the xanthophyll cycle (Cheng et al., 2000; Maxwell and Johnson, 2000). De-epoxidation of the xanthophylls contributes to the ability of thermal dissipation of excitation energy (DemmigAdams and Adams, 1996). DEPS increased in WRS leaves, indicating thermal dissipation ability of xanthophyll cycle pigments may be increased in WRS leaves (Fig. 4). However, HRS caused no obvious changes compared with CK (Fig. 4), indicating that excess leaf energy was not evident in contrast to WRS leaves. Compared with HRS and CK, the system of xanthophyll-dependent dissipation might be up-regulated in WRS leaves to prevent damage by excess light energy on Day 6 after initiating water stress.

In conclusion, both HRS and WRS influenced photosynthesis in leaves. The $P_{n}$ of HRS was affected mainly as a result of stomatal limitation throughout the experiment, whereas as water stress progressed, non-stomatal limitation occurred in WRS leaves. The effect of reduced photosynthesis was much greater on WRS than HRS trees. Further analysis of chlorophyll fluorescence showed little damages on the donor side of the PSII RCs under both WRS and HRS, but the acceptor side was markedly and non-reversibly damaged in WRS leaves. HRS had no influence on the acceptor side of the PSII RCs and on DEPS of leaves compared with CK. However, in WRS plants, DEPS was up-regulated to dissipate excess light energy as heat and protect leaves from photo damage.

\section{Literature Cited}

Asada, K. 1999. The water-water cycle in chloroplasts: Scavenging of active oxygens and dissipation of excess photons. Annu. Rev. Plant Physiol. Plant Mol. Biol. 50:601-639.

Bilger, W. and O. Björkman. 1990. Role of the xanthophyll cycle in photoprotection elucidated by measurements of light-induced absorbance changes, fluorescence and photosynthesis in leaves of Hedera canariensis. Photosynth. Res. 25:173-185.

Chaves, M. 1991. Effects of water deficits on carbon assimilation. J. Expt. Bot. 42:1-16.

Chen, H.X., H.Y. Gao, S.Z. An, and W.J. Li. 2004a. Dissipation of excess energy in Mehler-peroxidase reaction in Rumex leaves during salt shock. Photosynthetica 42:117-122.

Chen, H.X., W.J. Li, S.Z. An, and H.Y. Gao. 2004b. Characterization of PSII photochemistry and thermostability in salt-treated Rumex leaves. J. Plant Physiol. 161:257-264.

Cheng, L.L., L.H. Fuchigami, and P.J. Breen. 2000. Light absorption and partitioning in relation to nitrogen content in 'Fuji' apple leaves. J. Amer. Soc. Hort. Sci. 125:581-587.

Christen, D., S. Schönmann, M. Jermini, R.J. Strasser, and G. Défago. 2007. Characterization and early detection of grapevine (Vitis vinifera) stress responses to esca disease by in situ chlorophyll fluorescence and comparison with drought stress. Environ. Exp. Bot. 60:504-514.

Dai, J., H. Gao, Y. Dai, and Q. Zou. 2004. Changes in activity of energy dissipating mechanisms in wheat flag leaves during senescence. Plant Biol. 6:171-177.

Davies, W.J., S. Wilkinson, and B. Loveys. 2002. Stomatal control by chemical signalling and the exploitation of this mechanism to increase water use efficiency in agriculture. New Phytol. 153:449-460. Demmig-Adams, B. and W.W. Adams, III. 1996. The role of xanthophyll cycle carotenoids in the protection of photosynthesis. Trends Plant Sci. 1:21-26.

Dodd, I.C. 2009. Rhizosphere manipulations to maximize 'crop per drop' during deficit irrigation. J. Expt. Bot. 60:2454-2459.

Duan, W., P.G. Fan, L.J. Wang, W.D. Li, S.T. Yan, and S.H. Li. 2008. Photosynthetic response to low sink demand after fruit removal in relation to photoinhibition and photoprotection in peach trees. Tree Physiol. 28:123-132.

English, M., J. Musick, and V. Murty. 1990. Management of farm irrigation systems, p. 631-663. In: Hoffman, G.J., T.A. Howell, and K.H. Solomon (eds.). Management of farm irrigation systems. Amer. Soc. Agr. Eng., St. Joseph, MI.

Ennahli, S. and H.J. Earl. 2005. Physiological limitations to photosynthetic carbon assimilation in cotton under water stress. Crop Sci. 45:2374-2382.

Farquhar, G.D. and T.D. Sharkey. 1982. Stomatal conductance and photosynthesis. Annu. Rev. Plant Physiol. 33:317-345.

Genty, B., J.M. Briantais, and N.R. Baker. 1989. The relationship between the quantum yield of photosynthetic electron transport and 
quenching of chlorophyll fluorescence. BBA-Gen. Subjects 990: 87-92.

Horton, P., A.V. Ruban, and R.G. Walters. 1994. Regulation of light harvesting in green plants (indication by nonphotochemical quenching of chlorophyll fluorescence). Plant Physiol. 106:415-420.

Hsiao, T.C. 1973. Plant responses to water stress. Annu. Rev. Plant Physiol. 24:519-570.

Ivanov, B. and G. Edwards. 2000. Influence of ascorbate and the Mehler peroxidase reaction on non-photochemical quenching of chlorophyll fluorescence in maize mesophyll chloroplasts. Planta 210:765-774.

Jiang, C.D., H.Y. Gao, Q. Zou, G.M. Jiang, and L.H. Li. 2006. Leaf orientation, photorespiration and xanthophyll cycle protect young soybean leaves against high irradiance in field. Environ. Exp. Bot. 55:87-96.

Kang, S., L. Zhang, X. Hu, Z. Li, and P. Jerie. 2001. An improved water use efficiency for hot pepper grown under controlled alternate drip irrigation on partial roots. Sci. Hort. 89:257-267.

Kirda, C., S. Topcu, H. Kaman, A. Ulger, A. Yazici, M. Cetin, and M. Derici. 2005. Grain yield response and N-fertiliser recovery of maize under deficit irrigation. Field Crops Res. 93:132-141.

Kirilovsky, D.L., C. Vernotte, and A.L. Etienne. 1990. Protection from photoinhibition by low temperature in Synechocystis 6714 and in Chlamydomonas reinhardtii: Detection of an intermediary state. Biochemistry 29:8100-8106.

Kitajima, M. and W. Butler. 1975. Quenching of chlorophyll fluorescence and primary photochemistry in chloroplasts by dibromothymoquinone. BBA-Bioenergetics 376:105-115.

Lazár, D., J. Naus, M. Matousková, and M. Flasarová. 1997. Mathematical modeling of changes in chlorophyll fluorescence induction caused by herbicides. Pestic. Biochem. Physiol. 57:200-210.

Li, P.M., H.Y. Gao, and R.J. Strasser. 2005. Application of the fast chlorophyll fluorescence induction dynamics analysis in photosynthesis study. J. Plant Physiol. Mol. Biol. 31:559-566.

Li, T.H. and S.H. Li. 2005. Leaf responses of micropropagated apple plants to water stress: Nonstructural carbohydrate composition and regulatory role of metabolic enzymes. Tree Physiol. 25:495-504.

Liu, F., A. Shahnazari, M.N. Andersen, S.E. Jacobsen, and C.R. Jensen. 2006a. Effects of deficit irrigation (DI) and partial root drying (PRD) on gas exchange, biomass partitioning, and water use efficiency in potato. Sci. Hort. 109:113-117.

Liu, F., A. Shahnazari, M.N. Andersen, S.E. Jacobsen, and C.R. Jensen. 2006b. Physiological responses of potato (Solanum tuberosum L.) to partial root-zone drying: ABA signalling, leaf gas exchange, and water use efficiency. J. Expt. Bot. 57:3727-3735.

Long, S., S. Humphries, and P.G. Falkowski. 1994. Photoinhibition of photosynthesis in nature. Annu. Rev. Plant Biol. 45:633-662.
Lu, C. and J. Zhang. 1999. Effects of water stress on photosystem II photochemistry and its thermostability in wheat plants. J. Expt. Bot. 50:1199-1206.

Luo, H.B., L. Ma, H.F. Xi, W. Duan, S.H. Li, W. Loescher, J.F. Wang, and L.J. Wang. 2011. Photosynthetic responses to heat treatments at different temperatures and following recovery in grapevine (Vitis amurensis L.) leaves. PLoS One 6:e23033.

Maxwell, K. and G.N. Johnson. 2000. Chlorophyll fluorescenceA practical guide. J. Expt. Bot. 51:659-668.

Niyogi, K.K. 2000. Safety valves for photosynthesis. Curr. Opin. Plant Biol. 3:455-460.

Noctor, G., S. Veljovic-Jovanovic, S. Driscoll, L.N. Ovitskaya, and C.H. Foyer. 2002. Drought and oxidative load in the leaves of C3 plants: A predominant role for photorespiration? Ann. Bot. (Lond.) 89:841-850.

Ort, D.R. 2001. When there is too much light. Plant Physiol. 125:29-32.

Pieters, A.J., W. Tezara, and A. Herrera. 2003. Operation of the xanthophyll cycle and degradation of D1 protein in the inducible CAM plant, Talinum triangulare, under water deficit. Ann. Bot. (Lond.) 92:393-399.

Quick, W., M. Chaves, R. Wendler, M. David, M. Rodrigues, J. Passaharinho, J. Pereira, M. Adcock, R. Leegood, and M. Stitt. 1992. The effect of water stress on photosynthetic carbon metabolism in four species grown under field conditions. Plant Cell Environ. 15:25-35.

Sepaskhah, A. and S. Ahmadi. 2010. A review on partial root-zone drying irrigation. Intl. J. Plant Production. 4:241-258.

Shao, G., N. Liu, Z. Zhang, S. Yu, and C. Chen. 2010. Growth, yield and water use efficiency response of greenhouse-grown hot pepper under time-space deficit irrigation. Sci. Hort. 126:172-179.

Srivastava, A., B. Guissé, H. Greppin, and R.J. Strasser. 1997. Regulation of antenna structure and electron transport in photosystem II of Pisum sativum under elevated temperature probed by the fast polyphasic chlorophyll a fluorescence transient: OKJIP. BBA-Bioenergetics 1320:95-106.

Stoll, M., B. Loveys, and P. Dry. 2000. Hormonal changes induced by partial rootzone drying of irrigated grapevine. J. Expt. Bot. 51:1627-1634.

Strasser, B. and R. Strasser. 1995. Measuring fast fluorescence transients to address environmental questions: The JIP-test, p. 977-980. In: Mathis, P. (ed.). Photosynthesis: From light to biosphere. KAP Press, Dordrecht, The Netherlands.

Strasser, R. and M. Tsimilli-Michael. 2001. Stress in plants, from daily rhythm to global changes, detected and quantified by the JIP-test. Chimie Nouvelle 75:3321-3326.

Strasser, R.J., A. Srivastava, and Govindjee. 1995. Polyphasic chlorophyll a fluorescence transient in plants and cyanobacteria. Photochem. Photobiol. 61:32-42.

Thayer, S.S. and O. Björkman. 1990. Leaf xanthophyll content and composition in sun and shade determined by HPLC. Photosynth. Res. 23:331-343 